\title{
ALTERAÇÕES FISIOLÓGICAS E BIOQUÍMICAS DURANTE A EMBEBIÇÃO DE SEMENTES DE SUCUPIRA-PRETA (Bowdichia virgilioides Kunth.) ${ }^{1}$
}

\author{
KELINE SOUSA ALBUQUERQUE ${ }^{2}$, RENATO MENDES GUIMARÃES ${ }^{3}$, ISIS FERNANDA DE ALMEIDA4${ }^{4}$, \\ ALINE DA CONSOLAÇÃO SAMPAIO CLEMENTE ${ }^{4}$.
}

\begin{abstract}
RESUMO - Nessa pesquisa foi avaliado o comportamento das sementes de sucupira-preta durante a embebição, bem como as modificações em algumas proteínas durante esse processo. As sementes foram embebidas em rolo de papel umedecido, a $30^{\circ} \mathrm{C}$ e pesadas a cada 6 horas até a protrusão radicular de $50 \%$ das sementes, após o que as sementes foram submetidas a análises protéicas pela técnica da eletroforese. A curva de embebição dessa espécie segue um modelo trifásico. Na avaliação dos sistemas enzimáticos, foi observado um comportamento constante para as enzimas superóxido dismutase e malato desidrogenase. Para a enzima álcool desidrogenase, catalase e $\alpha$-amilase, a intensidade das bandas variou em função do lote utilizado. Para as proteínas resistentes ao calor, foi observada a presença de bandas durante toda a germinação, com alterações na intensidade no decorrer do processo.
\end{abstract}

Termos para indexação: espécie florestal, embebição, isoenzima, LEA proteína, eletroforese.

\section{PHYSIOLOGICAL AND BIOCHEMICAL ALTERATIONS DURING GERMINATION OF SUCUPIRA-PRETA (Bowdichia virgilioides Kunth.) SEEDS.}

\begin{abstract}
This research aimed to evaluate the alterations in black sucupira seeds during imbebetion and the modifications in some enzymes and proteins during this process. The seeds were imbibed in wet paper roll at $30^{\circ} \mathrm{C}$ and weighted for 6 hours until the root protrusion of $50 \%$ of the seeds, then the seeds were submitted to the protein analysis by electrophoresis technique. The imbebition curve of the black sucupira has a triphasic model. The evaluation of enzymatic systems shoed the same pattern for the enzymes superoxide dismutase and malate dehidrogenase. For the enzymes alcohol dehidrogenase, catalase and $\alpha$-amylase, the band intensity varied according to the seed lot used. For the protein resistant to heat, the presence of bands was observed throughout the germination, with alterations in intensity during the process.
\end{abstract}

Index terms: forest specie, soaking, isoenzyme, LEA protein, electrophoresis.

${ }^{1}$ Submetido em 03/03/2006. Aceito para publicação em 19/09/2006. Parte da Dissertação de Mestrado do primeiro autor, apresentada à Universidade Federal de Lavras (UFLA), financiada pelo CNPq.

${ }^{2}$ Eng. Agr., Doutoranda em Agronomia/Fitotecnia, UFLA, Lavras, MG, e-mail: kelinealbuquerque@yahoo.com.br.

${ }^{3}$ Eng. Agr.,Dr., Prof Adjunto, Departamento de Agricultura, UFLA, Cx. P. 37, CEP: 37200-000. Lavras-MG, e-mail: renatomg@ufla.br

${ }^{4}$ Estudantes de graduação do curso de Agronomia, UFLA, Lavras, MG. 


\section{INTRODUÇÃO}

A germinação de sementes consiste na reativação do crescimento do embrião por meio de uma seqüência ordenada de eventos metabólicos, resultando na ruptura do tegumento pela radícula. $\mathrm{O}$ início desse processo se dá pela absorção de água pelas sementes e termina com o alongamento do eixo embrionário (Bewley e Black, 1994).

A embebição é fundamental para a germinação porque permite a retomada da atividade metabólica, contribuindo para os processos de mobilização e assimilação de reservas e crescimento subseqüente (Marcos Filho, 2005). A velocidade de embebição depende das características de cada espécie, dentre essas, da composição química e da permeabilidade do tegumento.

Durante o processo de germinação das sementes varias enzimas estãoenvolvidas emreações metabólicas relacionadas à síntese e a degradação de moléculas. Assim essas enzimas podem ser utilizadas como marcadores moleculares para a elucidação dos eventos que ocorrem durante o processo de germinação. A enzima $\alpha$-amilase tem se mostrado eficiente para monitorar a intensidade de dormência de sementes de arroz ao longo do armazenamento; já a atividade da malato desidrogenase e da álcool desidrogenase permitem a avaliação da atividade respiratória. Ainda tem sido considerada no processo de germinação a atividade de enzimas removedoras de radicais livres, como catalase e superóxido dismutase, dentre outras, constituindo eficientes mecanismos de desintoxicação durante a embebição (McDonald, 1999).

A atividade dessas enzimas tem sido determinada por meio da técnica de eletroforese, a qual se constitui numa ferramenta eficiente para o acompanhamento das mudanças ocorridas durante o processo germinativo (Carraro, 1990). Outro fator importante no processo de embebição é a presença de proteínas resistentes ao calor.Essas proteínas estão relacionadas com a tolerância à dessecação de sementes de várias espécies, atuando como agentes protetores de componentes celulares, como membranas e outras proteínas (Black et al., 1999).

Pouco se conhece a respeito dos processos envolvidos na germinação de sementes de sucupira-preta. Dessa forma, no presente trabalho, foi estudada a curva de embebição, bem como os padrões de algumas enzimas e de proteínas resistentes ao calor durante o processo de germinação das sementes de sucupira-preta.

\section{MATERIAL E MÉTODOS}

O experimento foi conduzido no Laboratório Central de
Sementes do Departamento de Agricultura, da Universidade Federal de Lavras, Lavras, MG.

Foram utilizados dois lotes de sementes de sucupirapreta de diferentes procedências: o lote A foi coletado no município de Crato, CE, no ano de 2001 e foi armazenado em temperatura ambiente por três anos e o lote B coletado na cidade de Boa Vista, RR, em 2003 e armazenado em câmara com controle de temperatura e umidade por um ano. As sementes de cada lote foram armazenadas em sacos plásticos.

O grau de umidade foi determinado pelo método da estufa a $105^{\circ} \mathrm{C} \pm 3^{\circ} \mathrm{C}$, por 24 horas (Brasil, 1992). Foram utilizadas duas repetições, contendo um grama de sementes para cada lote e os resultados foram expressos em porcentagem.

Para a determinação da curva de embebição, foram utilizadas duas repetições de 50 sementes para cada tempo de embebição. Antes de iniciar a embebição, as sementes foram pesadas em balança analítica digital com precisão de $0,1 \mathrm{mg}$. Em seguida, os tegumentos foram escarificados com ácido sulfúrico concentrado durante 8 minutos e neutralizados com carbonato de cálcio a $2 \%$ por 3 minutos. A embebição foi realizada em rolos de papel germitest, umedecido com água destilada e mantidos em câmara de germinação a $30^{\circ} \mathrm{C}$. As sementes foram pesadas a cada 6 horas até a protrusão radicular de $50 \%$ das sementes.Após cada período de embebição, as sementes foram acondicionadas em deepfrezer para as análises enzimáticas. O ganho de peso (GP) das sementes foi calculado de acordo com a fórmula:

$$
G P=\left(\frac{P f-P i}{P i}\right) \times 100
$$

Em que: Pf: peso final (ganho de umidade a cada período de embebição).

Pi: peso inicial das sementes antes da embebição.

Durante a embebição selecionou-se uma semente para a avaliação do processo germinativo. Essa avaliação ocorreu de forma visual, observando as alterações morfológicas que ocorriam ao longo de 15 dias.

Para avaliação enzimática, as sementes foram maceradas sob gelo seco, contendo cerca de $0,05 \mathrm{~g}$ do antioxidante PVP (polivinilpirrolidone), e em seguida armazenadas em deepfreezer a $-84^{\circ} \mathrm{C}$, até o momento das análises das enzimáticas e de proteínas resistentes ao calor.

Para a extração das enzimas de sementes de sucupirapreta seguiu-se a metodologia utilizada por Menezes (2005) para sementes de soja, com algumas modificações. Cada período de embebição das sementes foi considerado um tratamento. 
Para cada isoenzima analisada, utilizaram-se $100 \mathrm{mg}$ do material macerado. Para a extração das isoenzimas, foram utilizados dois tampões: uma parte de tampão $0,2 \mathrm{M}$ de borato de lítio $(0,2 \mathrm{M}$ de hidróxido de lítio $\mathrm{pH} 8,3$, titulado com $2 \mathrm{M}$ de ácido bórico) para nove partes de tampão $0,2 \mathrm{M}$ de Tris citrato $\mathrm{pH} 6,5(0,2 \mathrm{M}$ de Tris base ph 6,5, titulado com $0,4 \mathrm{M}$ de ácido cítrico) e $0,15 \%$ de $\beta$-mercaptanol.

Em cada amostra de sementes, correspondente a cada tempo de embebição, foram aplicados $500 \mu \mathrm{L}$ do tampão de extração; as amostras foram agitadas em vortex e deixados em microtubos a $4^{\circ} \mathrm{C}$ overnight. Em seguida, foram centrifugadas a $16.000 \mathrm{xg}$ por 30 minutos a $4^{\circ} \mathrm{C}$. Foram aplicados $80 \mu \mathrm{L}$ do sobrenadante de cada amostra no gel de poliacrilamida $7,5 \%$ (gel separador) e 4,5\% (gel concentrador). Para a enzima $\alpha$-amilase, utilizou-se gel de poliacrilamida contendo 0,5\% de amido. O sistema tampão gel/eletrodo utilizado foi o Tris-glicina $\mathrm{pH} 8,9$ e a corrida eletroforética foi realizada por 4 horas, a uma voltagem constante de $150 \mathrm{~V}$. Após a eletroforese, os géis foram revelados para os sistemas álcool desidrogenase (ADH), malato desidrogenase (MDH), catalase (CAT), superóxido dismutase (SOD) e $\alpha$-amilase ( $\alpha$-AM) segundo Alfenas (1991).

Para a extração das proteínas resistentes ao calor, foi seguido o protocolo utilizado por Nery (2005), com algumas modificações. Pesaram-se 100mg do material macerado, provenientes de sementes submetidas aos diferentes tempos de embebição, em microtubos de $2 \mathrm{~mL}$ com $1.800 \mu \mathrm{L}$ de tampão de extração (50 mM Tris- $\mathrm{HCl} \mathrm{pH} 7,5 ; 0,5 \mathrm{M} \mathrm{NaCl}$, $0,005 \mathrm{M} \mathrm{MgCL}_{2}, 0,001 \mathrm{M}$ PMSF) e agitados em vortex. Em seguida, o material foi centrifugado a $14.000 \mathrm{xg}$ por 20 minutos a $4^{\circ} \mathrm{C}$ e o sobrenadante incubado em banho-maria a $80^{\circ} \mathrm{C}$ por 10 minutos e novamente centrifugado. Aos $100 \mu \mathrm{L}$ do sobrenadante foram adicionados $50 \mu \mathrm{L}$ de solução tampão da amostra (2,5mL de glicerol, 0,46g de SDS e 20mg de azul bromofenol) e colocados em banho-maria com água fervente por 5 minutos. A corrida eletroforética foi realizada por 4 horas a uma voltagem de $150 \mathrm{~V}$. Após a corrida, os géis foram corados em coomassie blue a $0,05 \%$, durante 15 horas e descolorados em solução de ácido acético $10 \%$, de acordo com Alfenas (1991).

A avaliação dos padrões protéicos foi feita de acordo com a intensidade das bandas, utilizando-se a superfície de um diafanoscópio.

\section{RESULTADOS E DISCUSSÃO}

O grau de umidade das sementes de sucupira-preta no momento da realização dos experimentos encontrava-se próximo aos $9 \%$.

Na Figura 1 está representada a evolução do processo germinativo das sementes de sucupira-preta. As primeiras manifestações do processo de embebição ocorreram algumas horas após a instalação do teste, caracterizada pelo intumescimento das sementes, observando-se aumento significativo no tamanho dessas, com mudança da sua coloração. Com 114 horas, ocorreu a protrusão da radícula das sementes do lote A; para as sementes do lote B essa protrusão ocorreu após 120 horas. Com o decorrer da germinação, foi observada a diferenciação da radícula e do hipocótilo, ocorrendo também a liberação dos cotilédones do tegumento, expandindo-se por volta do $10^{\circ}$ dia. A partir daí, começaram a surgir as primeiras raízes secundárias e os folíolos, o que ocorreu a partir do $15^{\circ}$ dia, caracterizando a plântula normal. A germinação das sementes de sucupirapreta foi caracterizada como epígea.
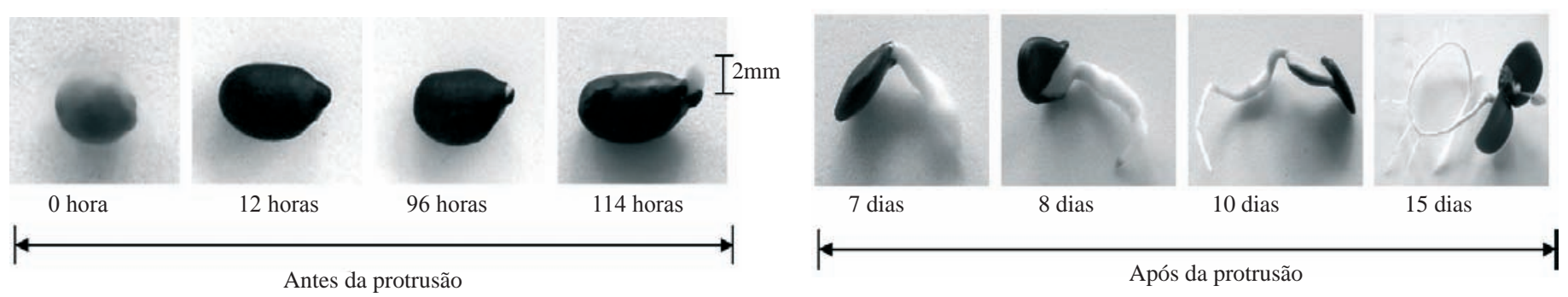

FIGURA 1. Evolução do processo germinativo de sementes de sucupira-preta (lote A), até a formação da plântula. UFLA, Lavras, MG, 2006.

Na Figura 2 encontra-se a curva de embebição para as sementes de sucupira-preta. Foram observados os períodos de
114 e de 120 horas para a ocorrência de protrusão da radícula das sementes do lote $\mathrm{A}$ e das do lote $\mathrm{B}$, respectivamente. 


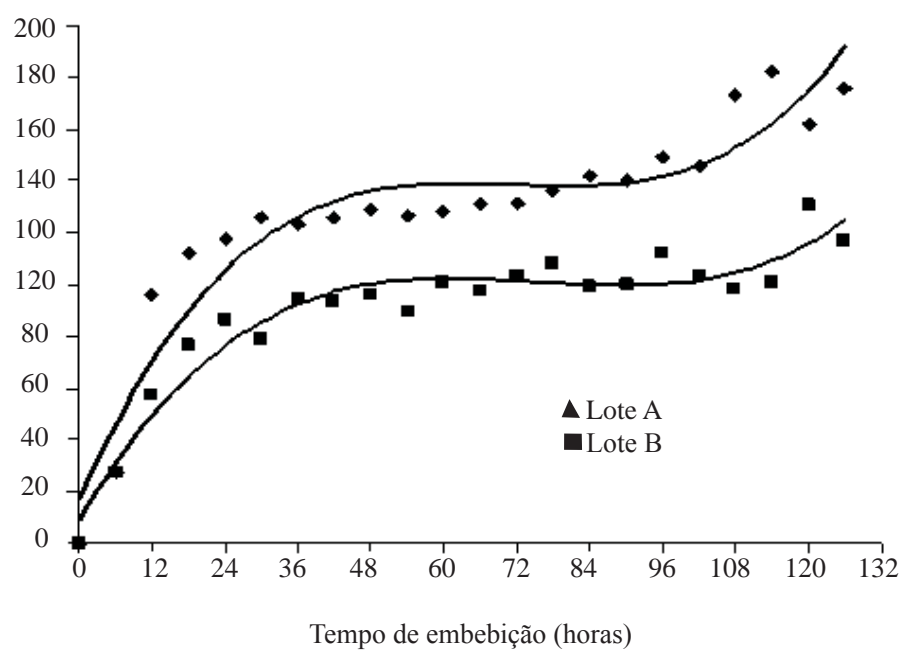

FIGURA 2. Curva de embebição de sementes de sucupirapreta. UFLA, Lavras, MG, 2006.

Observa-se, ainda, que a evolução da embebição da semente ocorre formando uma curva trifásica, sendo a fase I caracterizada por um ganho de umidade bastante significativo nas primeiras 12 horas de embebição para as sementes do lote A, em torno dos $100 \%$; já no lote B, a fase I ocorreu nas primeiras 24 horas de embebição e o ganho de umidade foi $20 \%$ inferior ao ganho das sementes do lote A. Essa diferença, provavelmente, ocorreu em função da idade das sementes, uma vez que foi observada a presença de sementes dormentes no lote B.

Resultados semelhantes foram relatados por Garcia \& Diniz (2003) que observaram uma rápida absorção de água nas primeiras 24 horas de embebição em sementes das espécies Vellozia gigantea N.L. Menezes e Vellozia variabili Mart. Ex Schult., e por Franco e Ferreira (2002) para Didymopanax morototonis (Aubl.) Dcne. Et Planch. Esses autores observaram ainda um período de oito horas na fase I do processo de embebição. Essa fase é caracterizada por ser um processo físico, pois independe da atividade metabólica das sementes, podendo ocorrer em sementes viáveis ou não (Bewley e Black, 1994). Segundo Seiffert (2003), este rápido ganho de umidade observado na fase I em relação às outras se deve, provavelmente, à presença de matrizes hidrofílicas, como proteínas. Marcos Filho (2005) descreve que, nessa fase surgem os primeiros sinais da reativação do metabolismo, com aumento acentuado da atividade respiratória, liberação de energia para a germinação e ativação de enzimas.

Para a espécie em estudo a fase II foi mais longa, durando em torno de 100 horas e com ganho de umidade mais lento. As sementes do lote A tiveram um crescente incremento no grau de umidade, enquanto que, nas do lote $\mathrm{B}$, observaramse várias oscilações ao longo dessa fase. Este fato pode ter ocorrido devido à presença, no lote $\mathrm{B}$, de algumas sementes que não tiveram sua dormência quebrada, por serem mais novas, enquanto que no lote A todas as sementes mostraramse embebidas. A redução drástica da velocidade de embebição e a intensidade de respiração são características dessa fase, cuja ocorrência e duração são variáveis de acordo com a espécie considerada. De acordo com Bewley e Black (1994), é necessária uma diminuição da absorção de água para a mobilização das substâncias que foram desdobradas na fase I da região de reserva para os tecidos meristemáticos.

Após esse período de reduzida embebição, as sementes voltaram a ganhar umidade, culminando com a protrusão radicular, caracterizando a fase III que, para as sementes do lote A, ocorreu após 114 horas de embebição e para o lote B após 120 horas. Isso se deve, provavelmente, a um estado de dormência menos intenso nas sementes do lote A, já que a dormência tende a diminuir com a idade da semente, facilitando assim a absorção de água. Essa retomada da embebição ocorreu devido à necessidade de água pelas novas células em processo de formação.

Os sistemas isoenzimáticos das sementes de sucupirapreta submetidas aos períodos de 0 a 126 horas de embebição revelados para álcool desidrogenase $(\mathrm{ADH})$, superóxido dismutase (SOD), catalase (CAT), malato desidrogenase (MDH) e $\alpha$-amilase ( $\alpha$-AM) estão apresentados nas Figuras 3, 4 e 5 .

Não foi observada atividade da enzima álcool desidrogenase (ADH) nas sementes do lote A nas primeiras horas de embebição. Entretanto, após 72 horas, observouse intensa atividade, decrescendo a partir desse período (Figura 3). No lote B, uma alta atividade da enzima foi detectada em sementes no início da absorção de água, com uma tendência de diminuição da atividade nas fases finais de embebição. A maior atividade da enzima observada no início da embebição de sementes do lote $\mathrm{B}$, pode ser atribuída à maior impermeabilidade do tegumento do que as do lote A, o que pode ter dificultado a entrada de oxigênio na semente, favorecendo, então, a rota de respiração anaeróbica, evitando, dessa forma, que as sementes ficassem expostas à ação deletéria do acetaldeído. À medida que a semente era exposta a maiores tempos de embebição, o tegumento tornava-se mais permeável, permitindo, dessa forma, o suprimento de oxigênio, justificando a diminuição da intensidade das bandas com o passar do tempo. 
Lote A
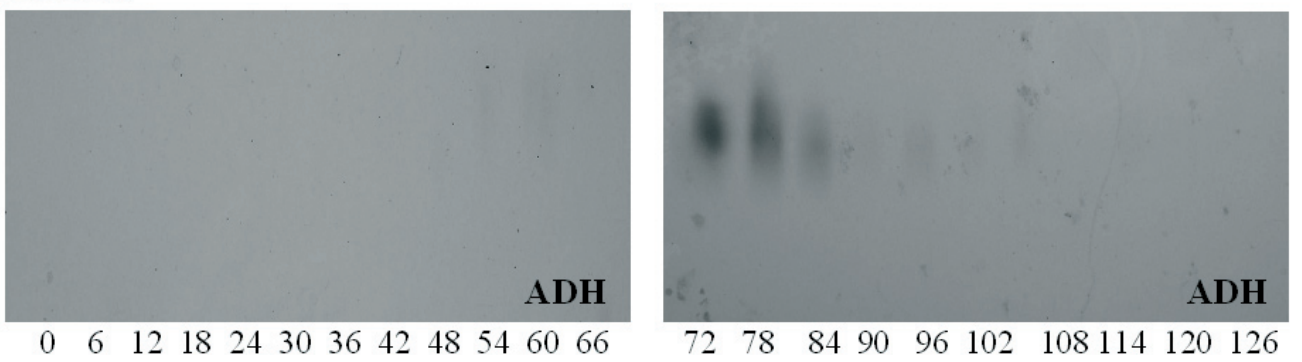

Lote B
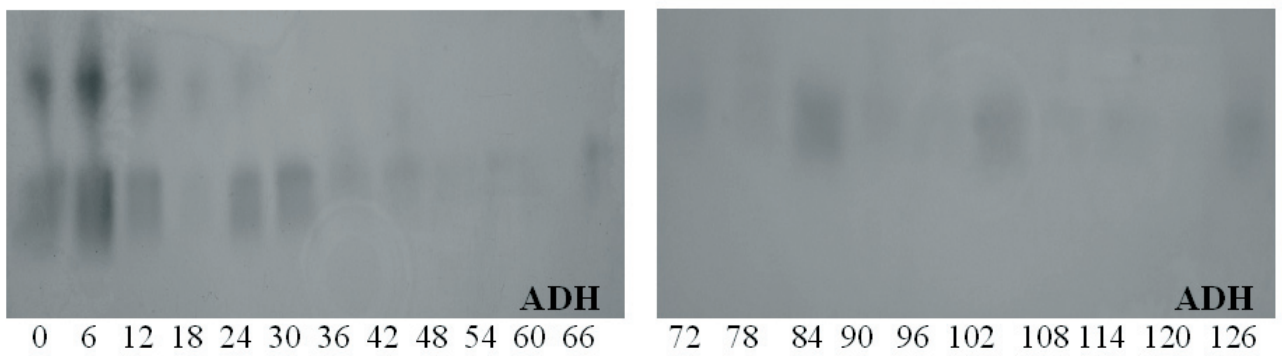

Lote A
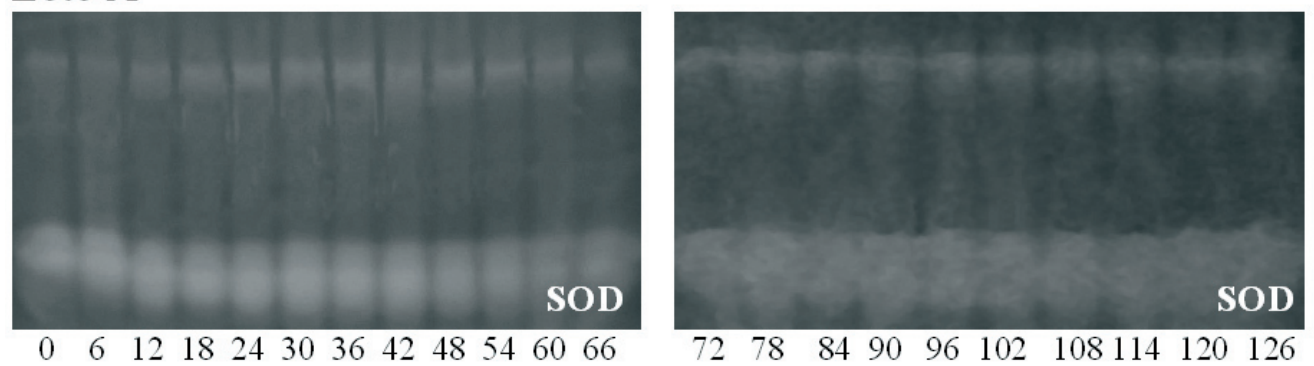

$\begin{array}{lllllllllllll}0 & 6 & 12 & 18 & 24 & 30 & 36 & 42 & 48 & 54 & 60 & 66\end{array}$

\section{Lote B}
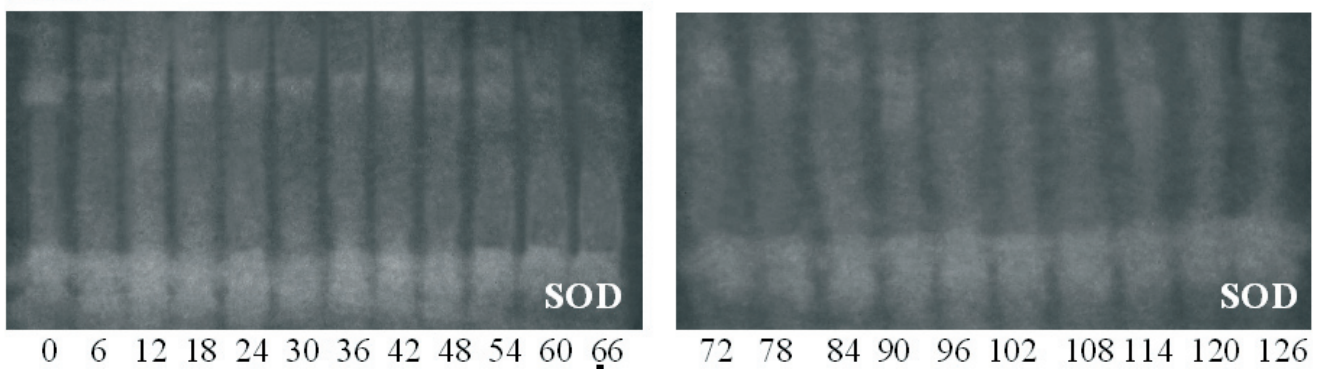

$\begin{array}{llllllllllll}0 & 6 & 12 & 18 & 24 & 30 & 36 & 42 & 48 & 54 & 60 & 66\end{array}$

FIGURA 3. Perfis enzimáticos da álcool desidrogenase (ADH) e superóxido dismutase (SOD) de dois lotes de sementes de sucupira-preta durante a germinação. UFLA, Lavras, MG, 2006.

As enzimas superóxido dismutase e catalase constituem eficientes mecanismos de desintoxicação, atuando na remoção de radicais livres (McDonald, 1999). Analisandose a atividade dessas enzimas, observou-se que não houve alteração do perfil enzimático da superóxido dismutase com o aumento do tempo de embebição, em ambos os lotes (Figura 3). Já o comportamento da catalase foi diferente entre os lotes e os períodos de embebição. Foi observada, nas primeiras horas de embebição, maior atividade da enzima nas sementes do lote $\mathrm{B}$, sendo a mesma reduzida à medida que as sementes avançavam no processo de germinação (Figura 4). Nas sementes do lote A, a enzima comportouse de forma inversa, sugerindo-se uma recuperação da sua atividade ao longo da germinação. De acordo com Jeng e 
Sung (1994), quando a semente é envelhecida, ocorre uma maior peroxidação dos lipídios e uma redução na atividade das enzimas removedoras de peróxidos, sugerindo que a

\section{Lote A}

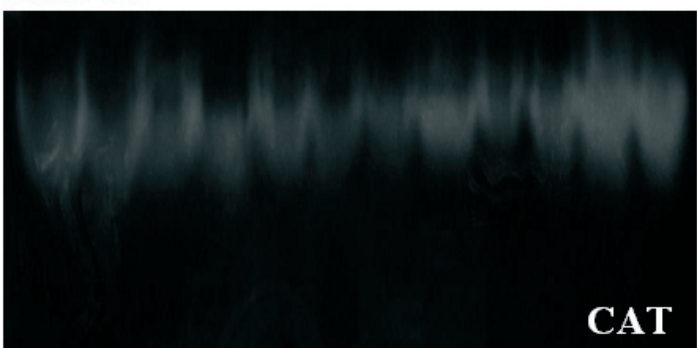

$\begin{array}{llllllllllll}0 & 6 & 12 & 18 & 24 & 30 & 36 & 42 & 48 & 54 & 60 & 66\end{array}$

\section{Lote B}

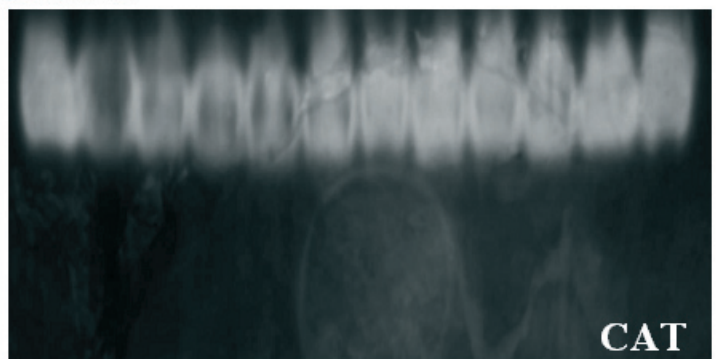

$\begin{array}{llllllllllll}0 & 6 & 12 & 18 & 24 & 30 & 36 & 42 & 48 & 54 & 60 & 66\end{array}$

Lote A

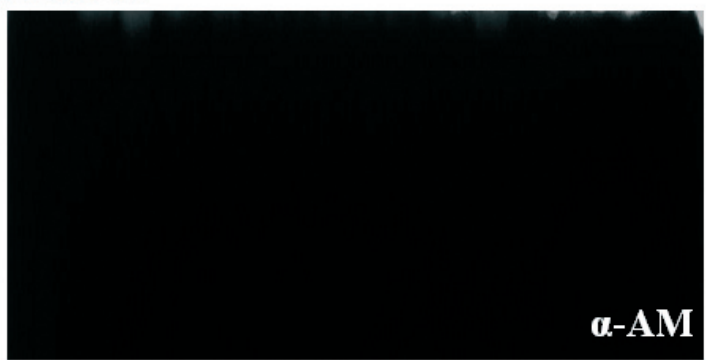

$\begin{array}{llllllllllll}0 & 6 & 12 & 18 & 24 & 30 & 36 & 42 & 48 & 54 & 60 & 66\end{array}$

\section{Lote B}

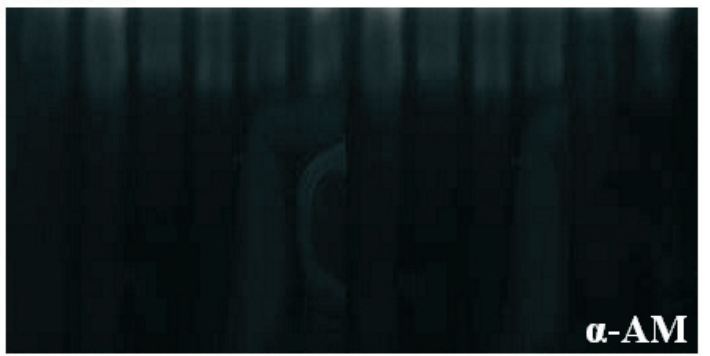

$\begin{array}{llllllllllll}0 & 6 & 12 & 18 & 24 & 30 & 36 & 42 & 48 & 54 & 60 & 66\end{array}$

diferença observada entre os lotes está relacionada com a idade das sementes.
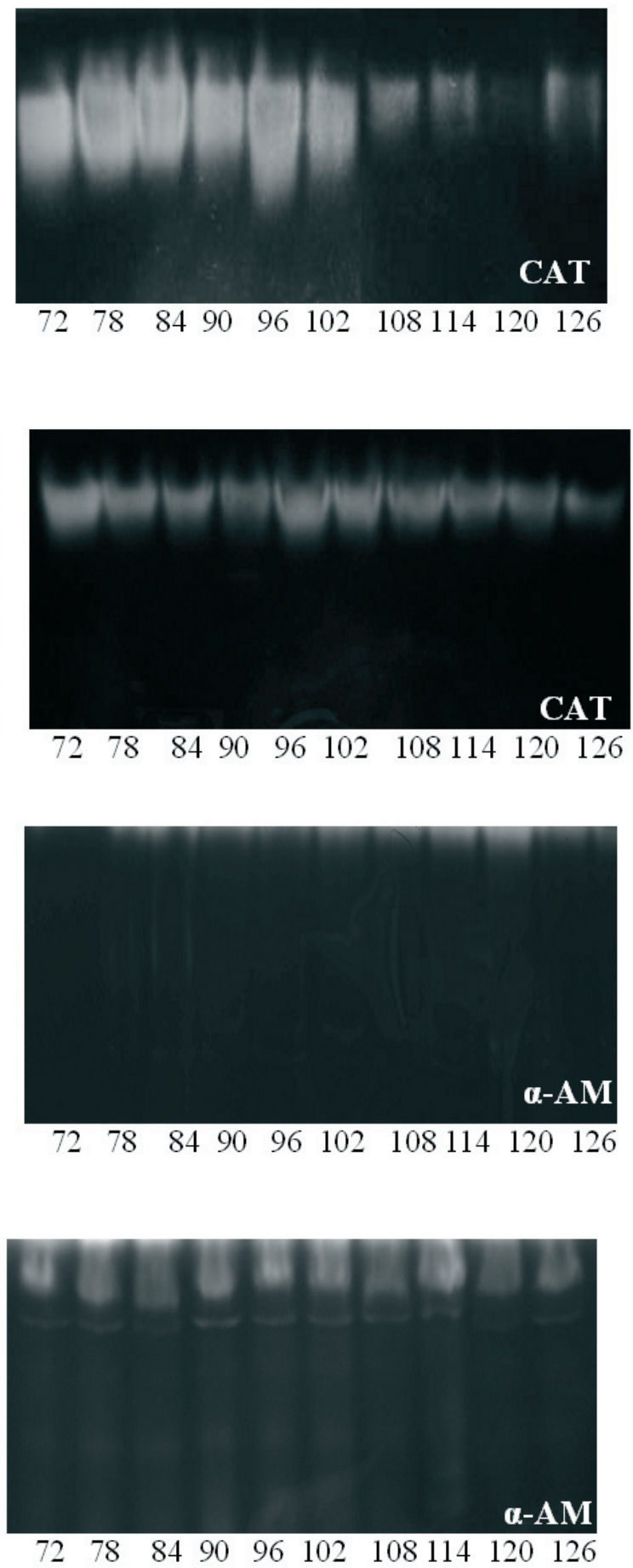

FIGURA 4. Perfis enzimáticos da catalase (CAT) e $\alpha$-amilase $(\alpha-A M)$ de dois lotes de sementes de sucupira-preta durante a germinação. UFLA, Lavras, MG, 2006. 
Resultados semelhantes foram obtidos por Basavarajappa et al. (1991), ao estudarem os efeitos do envelhecimento em sementes de milho, em que a intensidade das bandas da catalase diminuiu com o aumento do período de envelhecimento. Já Bailly et al. (1997) relataram que a enzima exerce papel relevante na germinação de sementes de girassol envelhecidas e que sua atividade tem sido fortemente correlacionada à recuperação da germinação por meio de tratamento de condicionamento.

Com relação à $\alpha$-amilase, foi observada intensa atividade dessa enzima apenas nas sementes do lote $\mathrm{B}$, ativada somente após 72 horas de embebição (Figura 4). O aparecimento dessa enzima depois de iniciado o processo de embebição deve-se ao fato dessa enzima ser sintetizada de novo durante a germinação, requerendo um determinado período para que essa nova síntese ocorra. Foi observada baixa atividade dessa enzima nas sementes do lote A e apenas no final da germinação. Esse comportamento pode estar relacionado com a idade das sementes do lote, o que é comprovado por diversos autores que observaram uma relação entre o envelhecimento dessas e o declínio na atividade da $\alpha$-amilase (Ganguli e Semandi, 1993; Fessel, 2005).

Com relação ao padrão enzimático da malato desidrogenase (Figura 5), foi observado, nas sementes do lote A, o surgimento de novas bandas após 48 horas de embebição, enquanto que, no lote $\mathrm{B}$, não foi observada alteração na atividade dessa com o avanço da germinação. A MDH tem papel relevante dentro do ciclo de Krebs, catalisando a conversão de malato a oxalacetato (Taiz e Zeiger, 2004).A recuperação de mitocôndrias com a indução dos reparos durante a germinação pode ser o motivo do aumento de bandas da MDH durante o processo.

\section{Lote A}

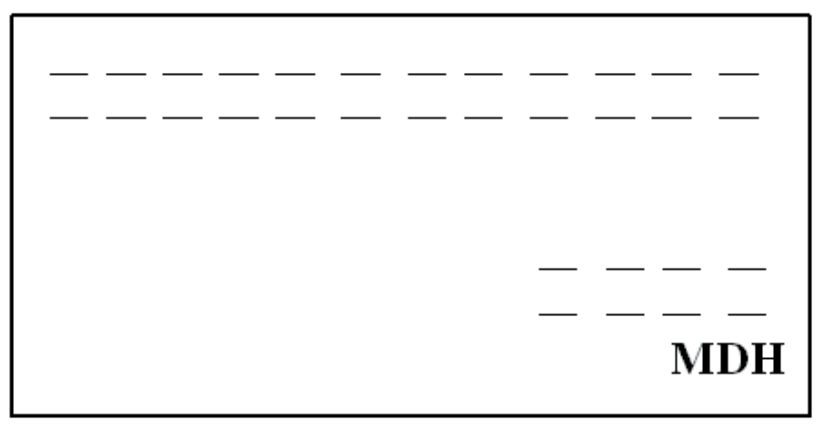

$\begin{array}{llllllllllll}0 & 6 & 12 & 18 & 24 & 30 & 36 & 42 & 48 & 54 & 60 & 66\end{array}$

Lote B

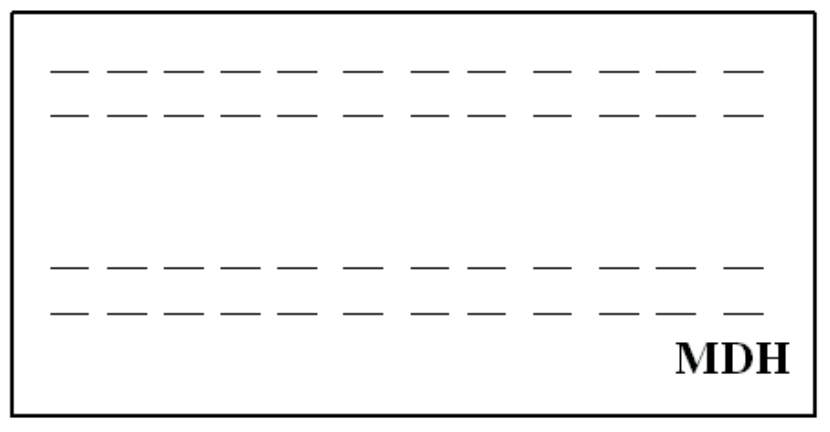

$\begin{array}{llllllllllll}0 & 6 & 12 & 18 & 24 & 30 & 36 & 42 & 48 & 54 & 60 & 66\end{array}$

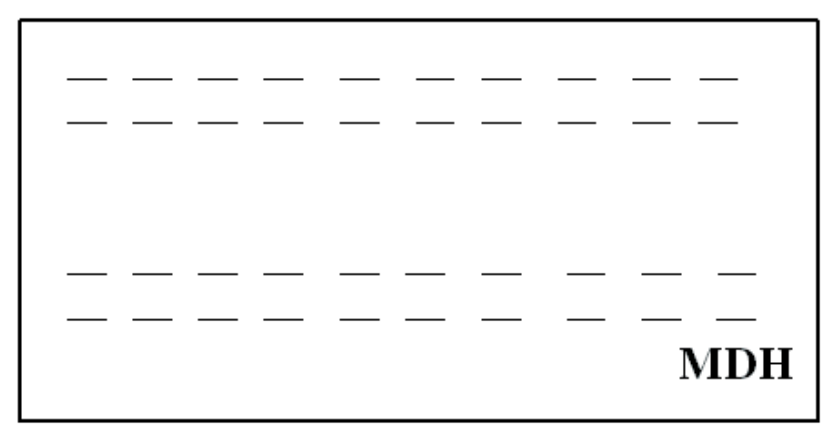

$\begin{array}{lllllllll}72 & 78 & 84 & 90 & 96 & 102 & 108 & 114 & 120126\end{array}$

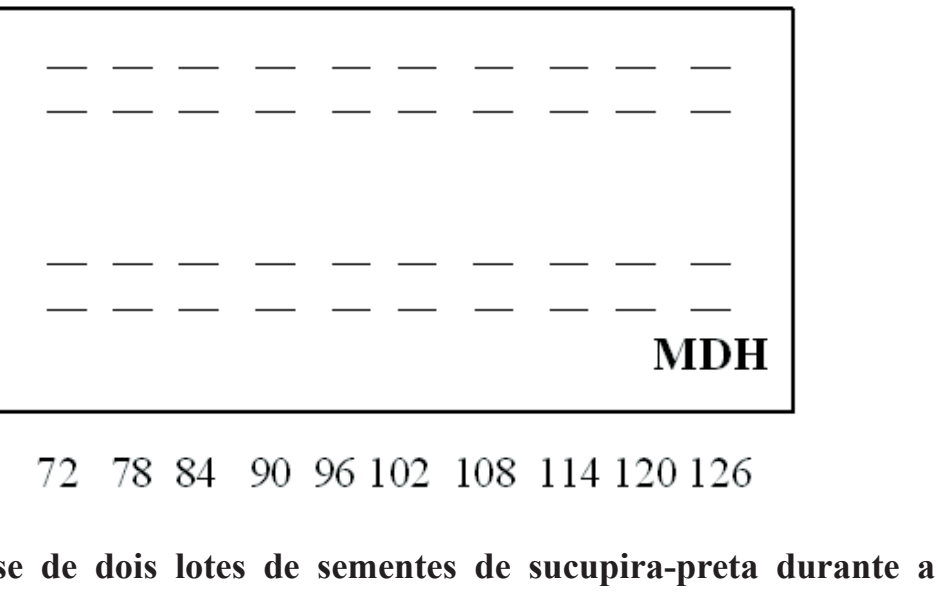
germinação. UFLA, Lavras, MG, 2006.

A atividade da $\mathrm{MDH}$ também tem sido relacionada ao processo de envelhecimento. Vieira (1996) observou aumento do número de bandas dessa enzima em sementes de algodão envelhecidas. Entretanto, Shatters et al. (1994) observaram que o aumento no número e ou intensidade de bandas da malato desidrogenase em sementes de soja submetidas ao envelhecimento foi menor, o que pode ter acontecido devido ao aumento da respiração que ocorre em 
sementes em processo de deterioração avançado. Já Spinola et al. (2000) não constataram alterações na atividade da malato desidrogenase em sementes de milho submetidas ao envelhecimento acelerado.

\section{Lote A}

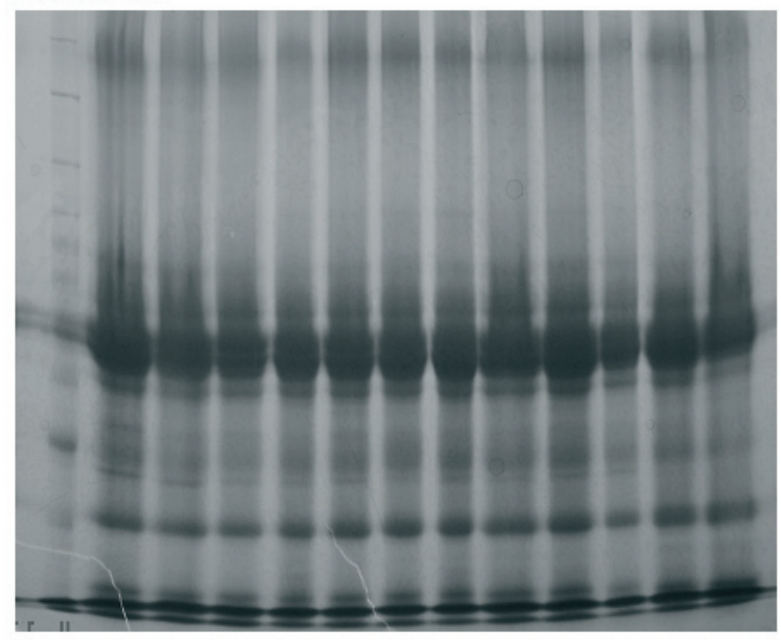

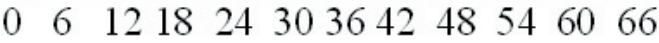

\section{Lote B}

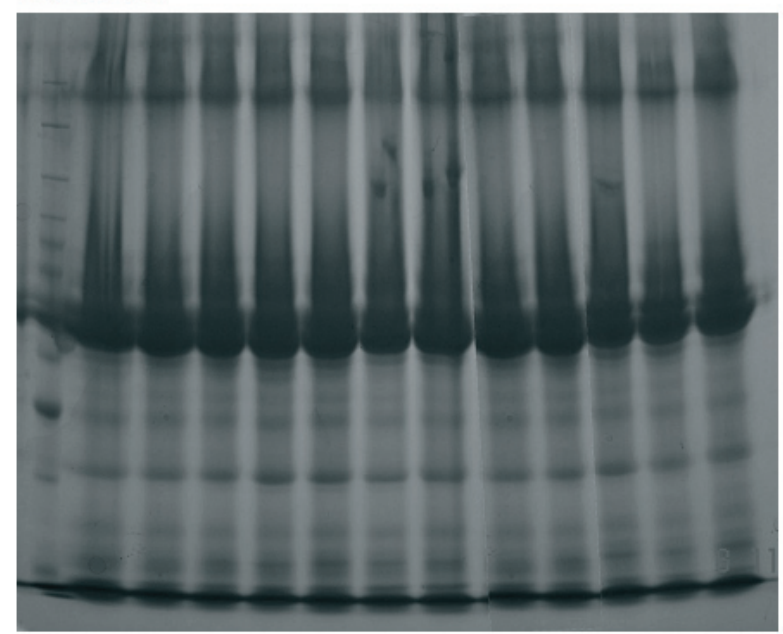

$\begin{array}{llllllllllll}0 & 6 & 12 & 18 & 24 & 30 & 36 & 42 & 48 & 54 & 60 & 66\end{array}$
$\mathrm{Na}$ Figura 6 observam-se os perfis eletroforéticos de proteínas resistentes ao calor para os dois lotes de sementes de sucupira-preta durante o processo de germinação.

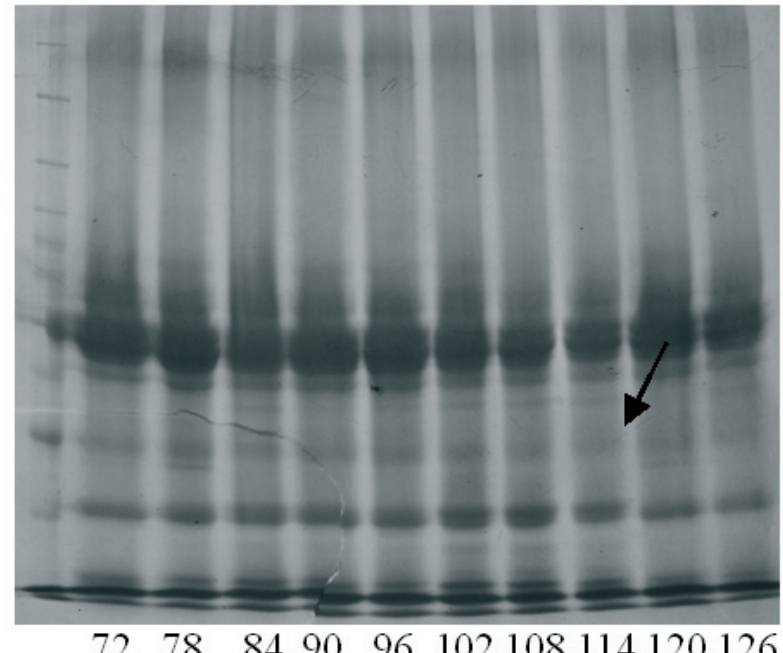

$\begin{array}{lllllll}72 & 78 & 84 & 90 & 96 & 102108114120126\end{array}$

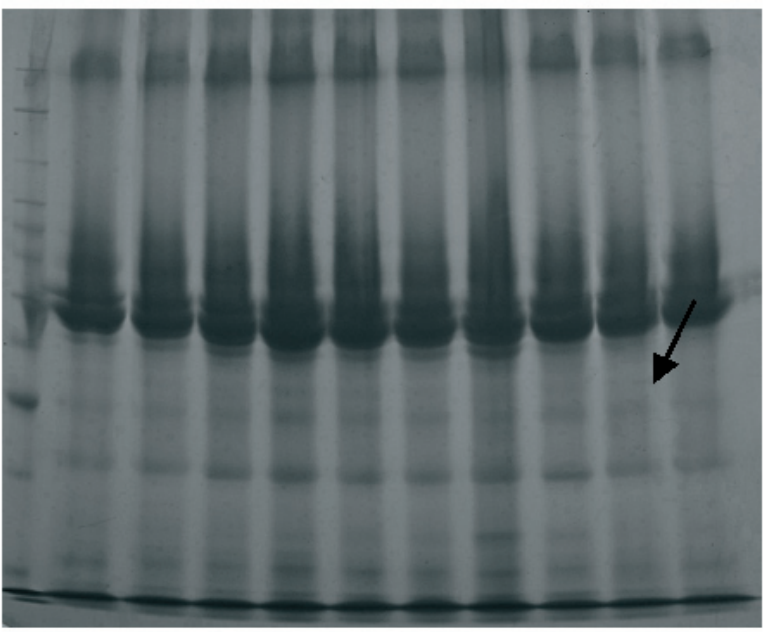

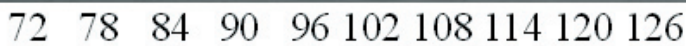

FIGURA 6. Perfis eletroforéticos de proteínas resistentes ao calor de sementes de sucupira-preta submetidas a diferentes tempos de embebição. Padrão Protein Ladder (P) de 220 a 10 KDa. UFLA, Lavras, MG, 2006.

Pôde ser observada a presença de proteínas resistentes ao calor durante todo o processo de germinação, as quais diminuem de intensidade à medida que se aproxima da protrusão radicular. Nas sementes do lote $\mathrm{B}$, houve maior número de bandas, principalmente as de baixo peso molecular. Nas sementes do lote A, o número de bandas foi mais estável, verificando-se uma diminuição da intensidade de algumas delas apenas no período mais avançado da germinação. Já nas sementes do lote $\mathrm{B}$, a diminuição dessas bandas já ocorreu após 72 horas de embebição.

Em estudos realizados por Walters et al. (1998) e Black et al. (1999) foi evidenciado que diversas proteínas do tipo 
LEA são acumuladas no final da maturação e que suas propriedades físicas de estabilidade, hidrofilicidade e sua abundância estão relacionadas com a tolerância à dessecação, garantindo a integridade das estruturas, permitindo a germinação da semente após a reidratação. Foi observada, no inicio do processo embebição, redução na quantidade de proteínas resistentes ao calor, com possível perda da capacidade de tolerância a dessecação.

\section{CONCLUSÕES}

O processo de embebição de sementes de sucupira-preta é caracterizado por uma curva trifásica, requerendo em torno de 114 a 120 horas para o início da protrusão radicular.

As análises isoenzimáticas permitem uma avaliação dos eventos bioquímicos ocorridos durante a germinação das sementes de sucupira-preta.

As proteínas resistentes ao calor são abundantes para a espécie estudada, mantendo-se presentes durante todo o processo germinativo, com alterações na intensidade das bandas com o avanço da germinação.

\section{REFERÊNCIAS}

ALFENAS, A.C.; PETRES, I.; BRUCE, W.; PASSADOS, G. C. Eletroforese de proteínas e isoenzimas de fungos e essências florestais. Viçosa: UFV, 1991. 242 p.

ASSOCIATION OF OFFICIAL ANALITICAL CHEMIST OFFICIAL. Methods of the association of official analitical chemists. 15. ed. Washington, 1990. 684 p.

BAILLY, C.; BENAMAR, A.; CORBINEAU, F.; CÔME, D. Changes in superoxide dismutase, catalase and glutatione reductase activities in sunflower seeds during accelerated ageing and subsequent priming. In: ELLIS, R. H.; BLACK, M.; MURDOCH, A. J.; HONG, T. D. (Ed.). Basic and applied aspects of seed biology. Boston: Kluwer Academic Publishing, 1997. p. 665-671.

BASAVARAJAPPA, B. S.; SHETTY, H. S.; PRAHASH, H. S. Membrane deterioration and other biochemical changes, associated with accelerated ageing of maize seeds. Seed Science and Technology, v. 18, n. 2, p. 297-310, 1990.

BEWLEY, J. D.; BLACK, M. Seeds: physiology of development and germination. 2ed. New York: Plenum Press, 1994. 445 p.

BLACK, M.; CORBINEAU, F.; GEE, H.; CÔME, D. Water content, rafinose and dehydrins in the induction of desiccation tolerance in immature wheat embryos. Plant Physiology, v.
120, n. 2, p. 463-471, June 1999.

BRASIL. Ministério da Agricultura e Reforma Agrária. Regras para análises de sementes. Brasília, DF: SNDA/ DNDV/CLAV, 1992. 365 p.

CARRARO, D. M. Variação e herança dos padrões eletroforéticos em órgãos e estágios de desenvolvimento em milho (Zea mays L.). 1990. 121 f. Dissertação (Mestrado em Fitotecnia) - Escola Superior de Agricultura "Luiz de Queiroz”, Universidade de São Paulo, Piracicaba.

FESSEL, S. A. Testes fisiológicos e eletroforese de enzimas para monitoramento da deterioração em sementes de milho. 2005. 139 f. Tese - Universidade Estadual Paulista, Jaboticabal.

FRANCO, E. T. H.; FERREIRA, A. G. Tratamentos prégerminativo em sementes de Didymopanax morototoni (Aubl.). Ciência Florestal, v. 12, n. 1, p. 1-10, jun. 2002.

GANGLI, S.; SENMANDI, S. Effects of ageing on amylase activity and scutellar cell structure during imbibition in wheat seed Annals of Botany, v. 71, n. 5, p. 411-416, 1993.

GARCIA, Q. S.; DINIZ, I. S. S. Comportamento germinativo de três espécies de Vellozia da Serra do Cipó. Acta Botânica Brasílica, v. 17, n. 4, p. 487-494, 2003.

JENG, T. L.; SUNG, J. M. Hydration effect on lipid peroxidation and peroxide scaveging enzymes activity of artificially age penault seed. Seed Science and Technology, v. 22, n. 3, p. 531-539, 1994.

MARCOS FILHO, J. Dormência de sementes. In: MARCOS FILHO, J. Fisiologia de sementes de plantas cultivadas. Piracicaba: FEALQ, 2005. p. 253-289

McDONALD, M. B. Seed deterioration: physiology, repair and assessment. Seed Science and Technology, v. 27, n. 1, p. 177-237, 1999.

MENEZES, M. Identificação de cultivares de milho, feijão, algodão e soja por meio de enzimas e de proteínas resistentes ao calor. 2005. 92 f. Dissertação (Mestrado em Fitotecnia) - Universidade Federal de Lavras, Lavras.

NERY, M. C. Aspectos morfofisiológicos do desenvolvimento de sementes de Tabebuia serratifolia Vahl Nich. 2005. 95 f. Dissertação (Mestrado em Fitotecnia) - Universidade Federal de Lavras.

SEIFFERT, M. Alguns aspectos fisiológicos e bioquímicos da germinação de sementes e anatomia foliar de Protium widgrenii Engler. 2003. 81 f. Dissertação (Mestrado em Fisiologia Vegetal) - Universidade Federal de Lavras, Lavras. 
SHATTERS JR, R. G.; ABDELGHANY, A.; ELBAGOURY, O.; WEST, S. H. Soybean deterioration and response to priming: changes in extracts from dry and germinatio seeds. Seed Science Research, v. 4, n. 1, p. 33-41, Mar 1994.

SPINOLA, M. C. M.; CÍCERO, S. M.; MELO, M. Alterações bioquímicas e fisiológicas em sementes de milho causadas pelo envelhecimento acelerado. Scientia Agrícola, v. 57, n. 2, p. 263-270, abr./jun. 2000.

TAIZ, L.; ZEIGER, E. Fisiologia vegetal. 3. ed. Porto
Alegre: Artmed, 2004. 719p.

VIEIRA, M. G. C. G. Utilização de marcadores moleculares no monitoramento da qualidade sanitária e nível de deterioração de sementes de algodoeiro (Gossypium hirsutum L.). 1996. 127f. Tese (Doutorado em Fitotecnia) Universidade Federal de Lavras, Lavras,

WALTERS, C. Understanding the mecanisms and kinetics of seed aging. Seed Science Research , v. 8, n. 2, p. 223244, June 1998. 